\title{
Research on Development Trend of Drainage Planning from the Perspective of Frequent Waterlogging Disasters
}

\author{
Jianhua Zhu ${ }^{1, a}$ \\ ${ }^{1}$ Huaibin County Urban and Rural Planning and Design Room, Huaibin, Henan, China, 464400 \\ aemail,
}

Keywords: Development Trend, Drainage Planning, Waterlogging Disasters

\begin{abstract}
At present, the accelerating process of urbanization in China although promotes economic development at a certain extent, but also highlights a variety of urban issues, including urban waterlogging. It has become the most difficult problem to be managed. In order to solve this problem effectively, it is necessary to carry on comprehensive and systematic analysis to the cause of its formation and consider the development of drainage planning, and formulate scientific and reasonable measures to prevent and control waterlogging in the city. Based on this, this paper first analyzes the status and causes of urban waterlogging disaster, and puts forward the development trend of urban drainage planning and the prevention and control measures of urban waterlogging.
\end{abstract}

\section{Introduction}

In nowadays, the social economy gets rapid development and China's urban scale has been expanding, with the subsequent urban development problems are more and more. In recent years, most of the cities in China have suffered different degrees of waterlogging disasters, especially in Beijing, Shanghai, Guangzhou and other large cities, waterlogging disaster is very serious, the whole city serious water, causing traffic paralysis, to people's lives and production Especially the "7.21" catastrophic flood disaster in Beijing not only brings serious impact on people's life, but also endangers people's life and health. The problem of urban waterlogging has become the focus of the government and the whole society. .

In recent years, a number of cities in different degrees of waterlogging, a number of large cities in the waterlogging, causing traffic 2012-2012 paralysis and had brought great impact on the people's lives and production. Especially in the July 21, 2012 Beijing suffered the largest in recent years, a rainfall attack, the city's average rainfall of $170 \mathrm{~mm}$ and the average urban rainfall of 215mm. One rainstorm center Hebei Fangshan District, the town of rainfall up to 541mm, the maximum rainfall of $95 \mathrm{~mm}$. The central city 63 main roads due to water caused traffic disruption, the city's population of 1,192,800 people, due to floods caused by direct economic losses of 11.835 billion RMB. Beijing "7.21" catastrophic floods caused a strong social repercussions and triggering the government and the community wide attention. The problem of urban waterlogging has become a major concern of the Chinese government, engineering and technical personnel and the general public.

In fact, urban waterlogging disasters in recent years have been plaguing the various cities, especially large cities. Ministry of Housing and Urban Construction in 2010, 321 provinces of 351 cities in the waterlogging survey shows that since 2008, 213 cities have occurred in varying degrees of waterlogging, accounting for $62 \%$ of surveyed cities; waterlogging disasters over a year More than three times the city has 137, or even extended to the drought of Xi'an, Shenyang and other western and northern cities. The cities with the waterlogging disaster exceeding the maximum water depth of $50 \mathrm{~mm}$ accounted for $74.6 \%$, the water depth was more than $90 \%$ of the $15 \mathrm{~mm}$. The cities with more than half an hour of stagnant water accounted for $78.9 \%$, among which 57 cities had a maximum waterlogging time of more than 12 hours.

\section{The Status of Urban Waterlogging}

Relevant survey statistics show that 351 cities in China, nearly $60 \%$ of the cities have occurred in 
varying degrees of waterlogging disasters, only between 2009-2011, more than three times the waterlogging disaster in the city there are more than 130 , In these cities, the maximum water depth of more than $50 \mathrm{~cm}$ of about $75 \%$, water depth of more than $15 \mathrm{~cm}$ up to $93.6 \%$, water time of more than $30 \mathrm{~min}$ of about $79 \%$, more than 50 cities in the water or even More than $12 \mathrm{~h}$. Beijing, Guangzhou, Shanghai, Changsha, Nanjing, Wuhan, Hangzhou and other cities due to heavy rain caused waterlogging situation has occurred. For example, May 12, 2011, Guangzhou City, heavy rain, resulting in a number of roads, "flooding Street" phenomenon, resulting in severe traffic congestion, many sections of the city are serious water phenomenon; June 23, 2011 Day, Beijing suffered a hundred years of heavy rain, local area road surface water more than $100 \mathrm{~mm}$, in this waterlogging disaster, there have been people accidentally fell into the drainage wells were washed away serious events, and street water disaster, July 17, 2011, Weihai City suffered heavy rain, rainfall in some areas up to $118.5 \mathrm{~mm}$, part of the urban section of serious water, the reservoir water level soared, July 25, the maximum precipitation reached 70 years in one case Of the $359 \mathrm{~mm}$, resulting in a large number of houses were damaged, roadbed slope damage, railway landslides, electrical facilities and communications equipment damage; June 28, 2011, Changsha City suffered a 20-year event of heavy rain, the maximum rainfall reached $130.8 \mathrm{~mm}$ August 12, 2011, Shanghai rainstorms, the largest $1 \mathrm{~h}$ rainfall up to $98.3 \mathrm{~mm}$, part of the street and the district serious water. The main street of the city,

\section{Analysis of the Causes of Cities Waterlogging Disasters}

The continuous development of urban construction, making the city gradually expanded and the urban waterlogging is becoming more and more serious. The frequent occurrence of waterlogging disasters in the city, to some extent, exposed the problems in the urban planning and construction. Analysis of the causes of waterlogging disasters, urban planning system, there are also reasons for the city's drainage system. In addition, the city's large-scale construction is to enlarge the impact of waterlogging on the city. The causes of urban waterlogging are very complex, and the specific reasons are related to different aspects, such as urban planning, municipal construction, but through comprehensive and systematic analysis, the causes of urban waterlogging are the following aspects.

Abnormal Weather Changes. The occurrence of waterlogging and weather conditions has a great relationship. In the global climate change, the growing greenhouse effect against the backdrop of the global climate anomalies continues to occur. Seasonal anomalies of atmospheric air flow, leading to extreme weather, rainfall increased. Many places are particularly prone to heavy rain, and some cities and even the unusual occurrence of a century of epic proportions of heavy rain. In addition, due to uneven distribution of rainfall in China's time and space, there will be strong rainfall in every summer. A short period of time the concentration of rainfall and it is very likely to cause urban drainage system failure and paralysis.

On the other hand, the rapid development of the city formed a strong heat island effect or rain island effect, changing the distribution of urban rainfall centers, as well as the intensity of rainfall. Coupled with the continuous expansion of the scale of municipal construction, roads, heat island effect is more prominent. The city will generate more heat, more likely to become the center of the region's heavy rain, so the frequency of rainstorms will be even higher.

The City's Water Cycle System Has Been Severely Damaged. Large-scale development of land in urban construction will cause changes in the topography of urban areas, to a certain extent, changed the original natural drainage system and the entire city's drainage system caused serious impact. Some of the discharge channels are filled and the storage capacity gradually reduced, the storm flood channel to reduce, causing urban waterlogging. In addition, the city's external development and construction, making some of the city outside the river flood into the city's river, leading to the city's flood capacity weakened. The city's water system is shrinking and the drainage system is not a better way out.

The Urban Surface Runoff is Abnormal. In the case of frequent occurrence of waterlogging disasters in the city, the analysis of surface runoff shows that the permeable area in the city is increasing and the concrete water storage area is decreasing. Ground subsidence and increased 
rainfall resulted in rain to the low-lying land pool, causing serious waterlogging.

The City's Original Pipe Network Planning and Design Cannot Adapt to the New Development and Changes. The safety and reliability of the rainwater system are closely related to the specific planning and design. Drainage facilities in the city are important cause of waterlogging. In the planning and design of drainage facilities, the return period is a very important parameter and it is based on the level of development of the city and a wide range of factors. As China's urban rainwater system design, the design of the return period is relatively low, easily lead to flooding.

Urban Drainage Design and Planning Is Not Perfect. The pace of urban construction continues to accelerate, making the area of the city continue to develop, changes in the urban terrain. For example, the previous upstream may become the current upstream, the original drainage system design is difficult to bear the ever-increasing amount of water and the old drainage pipes cannot afford more drainage requirements.

In addition, the city's drainage system construction mechanism is not perfect, under normal circumstances, the drainage system pipelines and road construction at the same time, but the specific construction of the main different, do not belong to the same sector management, therefore, road and drainage maintenance Synchronization, likely to cause drainage circuit, drainage and other export-free problems, the specific maintenance is not in place, will also frequent waterlogging.

\section{The Planning Countermeasures to Deal with Urban Waterlogging Disaster}

At present, the problem of urban drainage and the waterlogging problem of rainstorm has become the common concern of the society, which has been paid great attention by the government and leaders at all levels. Urban waterlogging problems, as well as urban water supply and drainage underground pipe network and other municipal infrastructure design and construction of less attention, have exposed the lack of urban planning and construction. Therefore, we must attach importance to urban development in the drainage planning issues, learn from the lessons of the past, increase the urban drainage facilities planning and construction and improve the city's flood discharge capacity.

In this context, the Chinese government has repeatedly proposed the scientific planning of urban construction, rational distribution. In order to solve the problem of urban waterlogging, put forward to strengthen the construction of urban underground pipe network, increase the standard of urban drainage, and urban drainage and waterlogging emergency scientific management. In addition, the causes of urban waterlogging disasters are closely related to the scale of urban construction, and also to the mode of urban development and construction. At present, the scale of urbanization in China is constantly expanding. In the past, the old urban drainage system cannot adapt to the new development needs. The urban construction changes have a greater impact on the drainage system.

In order to reduce the occurrence of urban waterlogging disasters, and strive to seek new urban construction model, the reform of urban drainage system to curb the causes of waterlogging disasters, completely solve the city's waterlogging disaster.

Do a Good Job of Drainage Planning. Existing statutory plans, although there are drainage planning contents, but most in name only, cannot really solve the problem. Urban planning in the drainage of professional planning, although the coverage is large, the depth is not enough. Line, blue line, green line, etc. are difficult to locate; detailed planning of the drainage of professional planning, although more detailed, there is a certain amount of time and space constraints, Depth, but the system is poor. From the drainage professional point of view, the current situation is a design, no planning. Drainage planning more focused on pipelines, pumping stations and other drainage facilities layout, the calculation is also to check the scale of the facilities, and the size of the drainage system convergence, pipeline and river convergence inadequate consideration, the lack of systematic planning.

Let us look at urban land planning and drainage planning convergence. Urban land classification does not take into account the relationship between land and surface runoff. Urban drainage layout is rarely considered when making urban land layout. In the case of urban vertical design and road vertical design, it rarely integrates rainwater utilization and emission, Poor drainage. For example, 
urban green space is a rare water-permeable surface, but many urban green spaces are higher than the road elevation cannot accept the nearby rainwater. Urban waterlogging prevention and control system engineering cannot be isolated, and rely on the "project with" to solve the key to planning and land use; project is no longer with the waterlogging problem cannot rely on pipeline pumping station to solve, In the overall planning stage reasonable to determine the layout of the drainage system, give priority to solve the drainage destination and large channel; multi-professional coordination and interaction, so that planning to adapt to the original natural water body, adapt to the original natural water storage and drainage conditions, in line with thousands of years The Mechanism of Water Circulation in Nature. Therefore, the urban planning is the top-level design of waterlogging prevention and control and good drainage planning is the key to prevention and treatment of waterlogging.

Construct the Large Drainage System. Foreign countries generally have two sets of urban drainage system. The small drainage system is mainly for the common rain conditions in the city. The heavy rain return period is usually from 2 to 10 years. The drainage system is collected through the conventional rainwater drainage system. The large drainage system is mainly aimed at the urban extraordinary rain conditions. It is composed of tunnels, greenbelt, water system, reservoirs and roads and cannot transmit the runoff through the surface drainage channel or underground drainage tunnel. The system can also be called urban waterlogging prevention and control system, is the delivery of high return period of storm water runoff drainage channel. Some countries will be the size of the drainage system known as the "double drainage system."

China is currently only a small drainage system, or called the pipeline system, in the existing planning system, there is no concept of a large drainage system, that is not clear urban waterlogging control system. China has built a flood control system at the basin level, with corresponding planning and design standards and technical standards, the purpose is to prevent water into the city; also has a set of urban pipe network drainage system and the corresponding standards, but for more than rain Network drainage capacity of the storm runoff is not that there is no unified design method, there is no relevant technical standards and planning and design specifications, of course, the lack of appropriate engineering facilities and integrated means.

\section{Conclusion}

In summary, the urban waterlogging disaster has become one of the main factors affecting the urban construction and development. In particular, some cities with frequent waterlogging disasters have been seriously affected. This problem must arouse our attention. A lot of practice shows that a reasonable and feasible urban drainage planning and improved drainage system can effectively prevent the occurrence of urban waterlogging disasters. To this end, the major cities should prepare scientific drainage planning and constantly improve the urban drainage system, this is only way to make the city waterlogging disaster problem being resolved fundamentally.

\section{References}

[1] Yin E, Xu Shiyuan. Journal of Geographical Sciences, Vol. 5 (2010) No 53, p.25-26

[2] Xing Wei, Zhao Dongquan. China Water Supply and Drainage, Vol. 20 (2011) No 27, p.74-76

[3] Sun Jie. Chinese Urban Planning, Vol. 12 (2012) No 19, p.144-145

[4] Yang Wenzhe. Chinese Population, Resources and Environment, Vol. 3 (2011) No 27, p.21-23

[5] Song Qier. Urban Roads Bridges \& Flood Control, Vol. 10(2010) No 27, p.57-60 